\title{
Impact of Self-Awareness and Self-Management on Organizational Commitment to Change: A Study Based on Aviation Industry in Sri Lanka
}

\author{
Warnakula, U.S. ${ }^{1}$, Dhammika, K.A.S. ${ }^{2}$, Karunarathne, R.A.I.C. ${ }^{3}$ \\ ${ }^{1}$ University of Kelaniya, Sri Lanka. \\ ${ }^{2}$ Department of Human Resource Management, University of Kelaniya, Sri Lanka. \\ ${ }^{3}$ Department of Human Resource Management, University of Kelaniya, Sri Lanka. \\ ${ }^{1}$ upulis.warnakula@gmail.com, ${ }^{2}$ kasdhammika@yahoo.com, ${ }^{3}$ ishankac@kln.ac.lk
}

\begin{abstract}
As organizations are operating in a turbulent environment, it is essential for them to change the existing practices and policies. Currently, the aviation sector in Sri Lanka needs to acclimatize to survive in their environment. Thus, this study aims to identify the impact of self-awareness and self-management on organizational commitment to change. Moreover, the study aims to examine the boundary conditions of the proposed relationship by examining the moderating effect of environmental dynamism, which received less attention in the extant literature. Researchers adopted post-positivism research philosophy, and the approach is deductive. Data were collected using a self-administrated questionnaire from 330 front-line employees in the aviation industry in Sri Lanka. PLS-SEM model was adopted to analyze the data, and the violating assumptions were tested. The results showed that self-awareness and self-management are positive and significant influences on organizational commitment to change, and environmental dynamism moderate these relationships. The key implication of this study is managing any critical times by inspiring their level of self-awareness and management to change the mindset of staff to cope with the organization change to enhance the commitment. The findings of the study are beneficial for potential aviation-related academies and partitioners.
\end{abstract}

Keywords: Aviation industry, Environmental dynamism, Organizational commitment to change, Self-awareness, Self-management

Copyright: (C) 2021 Warnakula, U.S., Dhammika, K.A.S., Karunarathne, R.A.I.C. This is an open access article distributed under the Creative Commons Attribution License, which permits unrestricted use, distribution, and reproduction in any medium, provided the original work is properly cited.

Correspondence: upulis.warnakula@gmail.com

ORCID of authors: K.A.S. Dhammika: (D https://orcid.org/0000-0002-3998-8066

R.A.I.C. Karunarathne: (D https://orcid.org/0000-0001-8528-7263

DOI: http://doi.org/10.4038/kjm.v10i2.7669 


\section{Introduction}

"The range of what we think and do is limited by what we fail to notice. And because we fail to notice that we fail to notice there is little we can do to change until we notice how failing to notice shapes our thoughts and deeds."

\section{— Daniel Goleman}

The emotional states are "a complex feeling state with psychic, somatic and behavioural factors which affect mood" (Kalpan \& Sadock, 1998, p.5226). It is a complex emotional and physiological fact involving an individual's state of mind and communication between individuals and their environment (Myers, 2001). Emotions are interconnected with mood, temperament, personality, attitude, and motivation. Ekman (1972) has classified "happiness, surprise, fear, disgust, anger \& sadness" as six principal emotions. Controlling own emotions and understanding other's emotions is the path to success in any person's day to day life and work-life (Goleman, 1995). In history, Mayer and Salovey (1990) scientifically defined emotional intelligence, which explains self-awareness and selfmanagement. Organization success depends on their employee's commitment towards the organization (Meyer, Stanley, Herscovitch, \& Topolnytsky, 2002). In recent years, the concept of organizational commitment has taken place as one of the main objectives in human resources management.

Previous studies evidence that organizational commitment to change can forecast a diversity of organizational outcomes, such as increased employee retention, reduced turnover, increasing job performance, lower absenteeism, and increased organizational citizenship behaviour (Sinha \& Jain, 2004). Furthermore, committed employees are the principal assets to the organization (Pfeffer, 1998). As shown by many types of research, organizational commitment is the main concept of commitment to the organization that performs healthier than those with lower levels of commitment. Self-efficiency is a principal competence in today's organization with changing attitudes and motivations. As per research's findings, self-awareness and self-management influence employee commitment (Steve, 2004). However, this research contributes to a significant relationship between self-awareness and selfmanagement organizational commitment to change (Rangriz \& Mehrabi, 2010).

Dynamic environments can be introduced by unpredictable, uncertain, and rapid changes, which would increase uncertainty for individuals and the organization's performance. Speeding environment involves organizations undergoing frequent changes (Judge \& Piccolo, 2004). Features like a modern financial crisis, political instability, environmental changes influence the organizations to change to compete to survive and remain competitive in the industry. The difference Between the actual output and the expected outcome would be the uncertainty (Duncan, 1972). The changing nature of the workforce, technological development speed, competitive pressure, and environmental change will increase the speed of change in the work environment. Due to this condition, employees probably experience high stress and anxiety levels (Waldman, Ramirez, House, \& Puranam, 2001).

The aviation industry has undergone striking amendments and policy changes due to environmental dynamism, globalization, growing competition and innovation technologies. With these changes, the organizations try to change their practices towards the organization vision. Moreover, aviation sector employees are experiencing a high level of pressure and stress, affecting their performance. Most airlines currently face merging, restructuring, and closedown of their organization (Cossin \& Caballero, 2013). The aviation industry has been struggling with various changes happing in the environment (Mack, 2014). There are issues faced by the aviation industry, such as changing economic conditions, intense 
competition, rising fuel prices, high customer expectation, air pollution, political environment, socio-cultural factors, technological changes, legal issues, environmental aspects and employee turnover (Choi, Lee \& Olson, 2015; Taneja, 2017; Lawton, 2017). In order to survive the organization, put constant pressure on their employees to committed work behaviour. Employee commitment is linked to factors with employee turnover, customer satisfaction, loyalty, productivity and profitability. The recent environmental crisis COVID -19 has affected the tourism industry with colossal pressure towards the aviation sector even though it is a transportation method.

The global aviation industry is an asset to a country in which airlines connect the power of aeroplanes to take passengers and cargo from one location to another with the collaboration of airports. The aviation industry provides 65.5 million jobs worldwide; it includes direct jobs within the airline industry, jobs supported to the industry's supply chain, employees' spending, and the aviation-enabled tourism sector. It provides $\$ 2.7$ trillion (3.6\%) of the world's gross domestic product (GDP)

In the Sri Lankan context, the service sector has been noted as demanded research context to examine. (Dissanayake\& Ismail, 2015; Nirmali, et.al.2018). In September 2017, the Sri Lankan government launched a development plan, vision 2025. The Air transport sector provides vas contribution to the country's economy. In Sir Lanka, the third biggest foreign exchange earner in the tourism industry. The airlines, airport operators, airport on-site enterprises (restaurants and retail), and air navigation service providers employ 19,000 people in Sri Lanka. Seven hundred three thousand jobs are supported by air transport and tourists arriving by air (IATA Economics 2018).

Airlines have been struggling to cope up with the competition that is generated in the airline industry. As a solution, airlines have chosen organizational change. In addition, the airline industry in Sri Lanka has been struggling to cope with the growing economy and competition. Mihin Lanka, the low-cost airline in Sri Lanka, ceased operations in 2016, 10 years after its commencement. Some of the famous airlines that ceased their operations by 2019 are Thomas Cook Airlines UK, LATAM US-based, Virgin Australia based in Australia, Mihin Lanka based in Sri Lanka, and Jet airways Ltd was an Indian international airline Mumbai.

In this stage, employees have to face critical situations with organizational change. The operational staff exert emotional labour, and they also have to face unexpected situations with their customers every day. Since aviation front line staff directly contact passengers for long periods, their behaviour and emotional attitude toward passengers heavily shape the customers' perception of the airline's image and the country's image. Due to the structural changes, aviation staff experience higher levels of stress and fatigue, resulting in some negative behavioural outcomes such as lack of commitment.

Self-awareness describes the person's internal states, likings, assets, and intuitions. It involves emotional awareness, which believes the core ability of EI, and the ability to know a person's strength and limits and self-confidence. Self-regulation illustrates managing employees' internal states, instincts, and capabilities. It contains six competencies: self-control, being trustworthy, conscientious, adaptable, taking the initiative, and having the drive to achieve. Environmental dynamism has become a threat to employee's emotions and reflects their commitment to change (Goleman \& Cherniss, 1998). Furthermore, the theories included in this will be the theory of social learning theory explains that a person is neither autonomous agents nor simply mechanical conveyors of animating environmental influences. This theory elaborates the way individuals grab, maintain and manage their behaviour while 
emphasizing the social environment the way individuals perform the behaviour (Wayne, 2019).

The theory of emotional capability describes gaining an understanding of the motivations, mindsets and beliefs of individuals that outline their emotions and how it will upgrade their commitment to change.

According to the (SLT) self-efficacy, determined the level of a person's confidence in his or her ability to successfully perform a behavior. Self-efficacy is unique to SCT, although other theories have added this construct later, such as the theory of planned behavior. Self-efficacy is unique to SCT, while other theories, such as the theory of planned behavior, have included it afterwards. Self-efficacy is determined by a person's unique qualities and other personal and contextual circumstances (barriers and facilitators).

According to Bandura (1997), self-awareness and self-management linked and show individuals view of organizational realities by recognizing thoughts, feelings, and behaviors through self-awareness, regulation, and control. In order to enable the front-line employees of the aviation industry in Sri Lanka to cope effectively, commitment to these demands and environmental dynamism, this study forces to explain the relationship between the employees' selfawareness, self-management and commitment change.

Environmental dynamism leads to organizational changes, and that leads to employee readiness to change. Employees have to face a situation such as an organizational culture change that embraces innovation, risk-taking, and learning supports organizational readiness for change (Madsen \& John, 2005). According to Bandura's theory, people with high self-efficacy, that is, those who believe they can perform well, are more likely to view complex tasks as something to be mastered rather than something to be avoided. According to the above mention statement, this can relate to the current study with high self-awareness, self-management and employees committed to even any environmental dynamism situations such as environmental upgrading's or downfalls in industry.

Emotional capability is connected to positive and negative emotions (McGuire, 1986), which relates to attitudes formation and alteration. Emotional capability is grounded on the presumption that self-awareness, selfmanagement is formed after an evaluation of an object. Once formed, they guide and drive behavior towards the cognitive dishonest (Ajzen, 2001). Employees' emotions structured with their attitudes, and emotions are supported by experience and what they receive outside (Eagly \& Chaiken, 1993). Environmental dynamism may contribute negative concerns for organizational commitment to change by generating fears to this current fit between the firm and its environment (Walters \& Bhuian, 2004).

At the organizational level, consistent with Huy's (1999, 2002, 2005) model, an emotionally capable organization will systematically perform appropriate emotion regulation actions or routines (called emotional dynamics) that attend to organization members' emotions elicited by stressful events a significant change. Feelings can act as important information under uncertainty (Schwarz, 1990). This study aims to research how this relationship is impacted under highly uncertain and dynamic external conditions.

The objectives of the study are, to determine the relationship between self-awareness and self-management their organizational commitment to change when there is an organization change happening. Among the frontline staff of aviation in Sri Lanka, the contribution of each of the significant predictor variables towards organizational commitment to change, and whether the selfawareness and self-management is useful for the study on moderating variables in the relationship between environmental 
dynamism and organizational commitment to change. In this study, researcher attempt to attain following research objective as a general objective, to examine the impact of self-awareness and self-management and organizational commitment to change and how this relationship varies across environmental dynamism. In addition, researcher developed specific objectives with the aim, to examine the significant impact of self-awareness and organizational commitment to change, to examine significant impact of self-management and organizational commitment to change, to examine the moderating impact of environmental dynamism on the relationship between self-awareness and organizational commitment to change, to examine the moderating impact of environmental dynamism on the relationship between selfmanagement and organizational commitment to change.

This study examines how self-related awareness and management change the perception of employees' views towards the commitment to an organizational change. Mainly this focuses on employee commitment to an unstable environment.

\section{Literature Review}

In 1983, Arlie Hochschild characterized the theory of 'Emotional Labour'. Emotional labour has become an important segment of most service sector organizations. Handling emotions has become a vital part of every organization as a set of laws. The administrations and the employees believe the terminology of emotional expressions and suppression is vital to influencing the customers and pathway to fulfil the organization goals.

According to Hochschild, jobs connecting with face to face or voice to voice interactions with customers, jobs demanding the employee to crop and modify an emotional state in the other person, and jobs permitting the employer to contrivance a certain amount of control over the emotional behaviours of the employees, produce or create emotional labour among the employees. The expression of organizationally requisite emotions that contradicts the truly felt emotions results in emotional dissonance (Hochschild, 1983). This disagreement between the felt and expressed emotions is challenging, resulting in psychological tension that negatively affects employees' health (Hochschild, 1983).

The emotional Intelligence concept has been revealed to implement diverse organizational activities and personal life situations. People with high (emotional intelligence) selfawareness, self-management level may use it to manage their emotions to develop a positive social relationship (Wong \& Law, 2002). In an organizational context, the positive social relationship helps develop employees positive work environment it can lead to committed employees. In this study, self-awareness and self-management will be linked to organizational commitment in an uncertain environment with environmental dynamism.

Self-awareness describes the person's internal states, likings, assets, and intuitions. It involves emotional awareness, which believes the core ability of emotional intelligence, and ability to know person's strength and limits and self-confidence. Selfmanagement illustrates the managing employees' internal states, instincts, and capabilities. It contains six competencies, including self-control, being trustworthy, conscientious, adaptable, taking initiative, and having a drive to achieve.

Meyer and Allen (1991) specify empirical support that organizational commitment is a multidimensional perception that provides a wide-ranging insight into the link between the organization and emotional labour. Affective commitment mentions the employee's emotional attachment to, relationship with, and involvement in the organization. Employees with high affective 
commitment last employment with the organization because they want to do so. Further, continuance commitment mentions the awareness of the costs involved with leaving the organization. Employees are primary link to the organization is based on continuance commitment remain because they need to do so, while; normative commitment reflects a feeling of obligation to continue employment.

Organizational commitment to change as employee outcome has a strong relationship with self-awareness and self-regulation (Wong \& Law, 2002). The study done by Adeyemo (2007) discovered the organizational commitment is a part of job satisfaction. When employees meet their needs, their level of commitment is high. Most of the previous studies show that selfawareness and self-regulation may have a direct and indirect influence on emotional labour and their commitment to change (Gardner \& Stough, 2003)

Nowadays, in the aviation industry, adopt strategies such as mergers and restructuring due to the environmental dynamism. Organizational change has become a common trend for the modern world (Albert, Ashforth, \& Dutton, 2000; Reilly, Brett, \& Stroh, 1993). Most organizations use various changing events such as mergers and acquisitions (restructurings, downsizing, layoffs, and new strategic initiatives.) That impacts what people perform, how they perform their tasks, their responsibilities and accountabilities. Previous findings have shown that successful organizational changes can refresh the companies, which went through down falling through cooperate turnaround (Hofer, 1980; Bibeault, 1982; Hambrick \& Schecter, 1983; Barker \& Duhaime, 1997).

The environmental dynamism creates uncertainty, anxiety, and stress in people, leading to resistance to change. In most cases, this is natural due to the perception of change (Connor, 1993). To change the perception of the employees will be depending on the change in top management attitude. Their role should be generating a sense of endurance for their employees in the mindset to a new environment are essential (Boselie \& Koene, 2010; Lamm \& Gordon, 2010; Dijk \& Van, 2009). The emotional labour behaviour and approach is a prominent part of the airline industry. That may lead to change their perceptions and positively and effectively influence the commitment towards organizational changes (Bass \& Riggio, 2006; Groves, 2005).

Various researchers have agreed that in today's dynamic environment, firms should be ambidextrous. Bring into line and effective in their management style of demand and at the same time should meet the demands of the environment that combat tomorrow (Duncan 1976; March 1991). Rapid and unpredictable change is considered a dynamic environment that would increase the uncertainty of employees' commitment within themselves (Dess \& Beard, 1984; Duncan, 1972). Uncertainty is the difference between predicted and actual outcomes (Simon, 1955).

Environmental dynamism has a moderating effect of uncertainty on the relationship between self-awareness, self-regulation and organizational commitment. According to (Homburg, Krohmer, \& Workman, 1999), top management tends to have less commitment and performance in dynamic and uncertain than stable environments. The moderating influence of the environment on decision behaviour and organizational commitment has been considered.

Environmental dynamism was considered to be the moderating factor as per literature. researchers attempt to examine the relationship between self- awareness and self-regulation and organizational commitment to change and environmental dynamism as a moderating variable. It has been theoretically and empirically justified the relationships of the variables. 
The conceptual frameworks are generally useful to quantify the data in order construct the causal associations between the constructs identified in the research (Malhotra, Agrawal \& Pererson, 1996). Based on the critically reviewed past studies, empirical and practical justifications, the conceptual framework of the study was constructed as Figure 01.

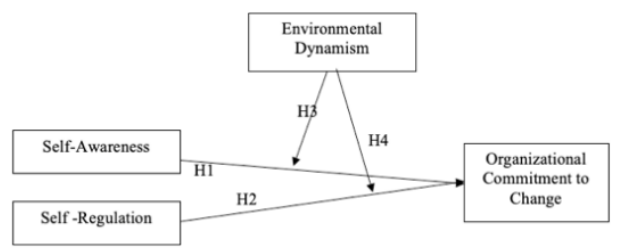

Figure 01: conceptual framework

This study expects to find out the relationship between self-awareness, self-regulation and organizational commitment to change in environmental dynamism on the aviation industry in the Sri Lankan context. This framework included the Goleman (2001) model of emotional intelligence and Herscovitch and Meyer (2002) model of organizational commitment to change. Further, the relationship between selfawareness, self-regulation and organizational commitment to change is moderated by environmental dynamism. This study has selected the Goleman Model due to its practical background. The employee organizational commitment to change chosen the Herscovitch and Meyer (2002) model due to its compatibility to study topic. An environment of an organization is the concept that includes material and social factors that taken into account directly during an organization change (Li \& Liu, 2014). In literature there are several explanations on environmental dynamism. In this study selects few interpretations which explain the concept of environmental dynamism.

\section{Hypotheses Development}

Sekaran and Bougi (2017) recognized the principal variables in a condition and examined the relationships among variables through logical reasoning in the theoretical framework. The hypothesis can be defined as a tentative yet demonstrable statement that predicts what is expected to be found in the empirical data (Sekaran \& Bougi, 2017).

\section{Self-awareness and organizational commitment to change}

The studies show that the relationship between self-awareness and organizational commitment to change has been broadly examined (Armenakis, Harris, \& Feild, 1999). This will assist employees in identifying their own emotions, abilities and managing emotions at work. Employees with a good level of self-awareness are committed to any organization changes and compatible with the organization's decisions (Erikkson, 2004). Self-awareness is a deep understanding of an individual regarding his emotions, needs, thoughts, strengths, weaknesses. According to Goleman (2001), self-aware individuals can understand what they need, evaluate those needs, and know when and how to tackle those needs accordingly. A study conducted using emotional labor in Malaysia shows a significant and positive relationship between self-awareness and organizational commitment (Mohamad \& Jais, 2016).

H1: There is a significant impact of selfawareness on organizational commitment to change.

\section{Self-regulation and organizational commitment to change}

Employees who know and can regulate their emotions are more likely to react to a problem in a more controlled manner and maybe more accommodative to different views of the subordinates. Understanding and regulating one's emotions and understanding others' emotions are factors that affect interpersonal relations, which means that leaders with the skill of self-regulation may influence employees' organizational commitment (Salami, 2008). Employees who 
have self-management skills can manage stress and remain calm in conflict, which may create a good working environment in an organization. Salami (2008) supports this by finding that understanding and regulating one's emotions and understanding others' emotions affect intrapersonal well-being and interpersonal relations, which influence the organizational commitment to change.

$\mathrm{H} 2$ : There is a significant impact of selfregulation on the organizational commitment to change.

Moderating effect of environmental dynamism on the relationship between the self-awareness, self-regulation and organizational commitment to change

The literature shows that the impact of emotional capabilities and organizational commitment on firm operations has a connection with environmental conditions like environmental dynamism (McArthur \& Nystrom, 1991). When the organization has to operate in dynamic environments due to different behavior, employees can detect and respond to unanticipated problems and opportunities (Zammuto \& O'Connor, 1992). For example, suppose the organization has employees with higher levels of emotional flexibility. In that case, they may be ready to adapt quickly to changes in their dynamic environment since the organization uses team-based work assignments, with individual team members exercising greater control over what specific task they perform. Employees with a positive attitude can alter to rapidly changing environments by committing themselves in different ways by changes in the availability, culture and nature change in technological developments, competitors' strategies and changes in customer needs and predilections (Motodwidlo \& Schmit, 1999). Hence, the following hypothesis is formulated,

$\mathrm{H} 3$ : there is a moderating impact of environmental dynamism on the relationship between self-awareness and organizational commitment to change

$\mathrm{H} 4$ : there is a moderating impact of environmental dynamism on the relationship between self-regulation and organizational commitment to change

\section{Methodology}

A post-positivism philosophy, using structured methods to facilitate study, was applied to this current study (Saunders \& Lewis, 2012). The study combines understanding self-awareness, selfregulation, organizational commitment to change and environmental dynamism to conduct quantitative data analysis. This is a cross-sectional study, where data was collected through a structured survey on front line staff of the aviation industry in Sri Lanka. The research method will be the deductive approach. Gratton \& Jones (2009) explained that deductive reasoning is about testing a pre-determined theory, description, or hypothesis.

The target population for this study is the front-line employees of the aviation sector. The population were 2300 front line staff related to the aviation sector in Sri Lanka. The unit of analysis has been defined by Sedgwick (2014) statistically with the "who" or "what" (Sedgwick, 2014). Accordingly, the unit of analysis of the current study is defined as the front-line staff of aviation industry in Sri Lanka.

The scholar will be using a stratified random sampling method in selecting employees who are directly dealing with customers in the aviation industry in Sir Lanka. According to the Zikmund (2003) population is a group that sharing and represents a same set of ideas.

The study population will be the 2300 Front line staff at aviation industry in Sri Lanka. It includes cabin crew, ground crew, airport service agents, employees at foreign beuro in 
Sri Lanka. In this study, among the population of 2300 front line staff, that sample size would be 330 .

A self-administered open-ended questionnaire and seven-point Likert scale questionnaire will be developing by using previous studies. The research method will be a survey method, and the instrument used will be a structured questionnaire for data collection. Likert questionnaire format and scale type questions will be developed and circulated to collect the data required. Each item is scored on a seven-point Likert scale ( 1 = Strongly Disagree; 7 = Strongly Agree $)$.

Accordig to the previous literature the operationalization has been elaborates each variable and the factors adopted. This framework included the Goleman (2001) model of emotional intelligence and Herscovitch and Meyer (2002) model of organizational commitment to change. Daniel Goleman, an American psychologist, developed a model of four elements that describe emotional intelligence. Selfawareness- Self-management is measured using 8 factors have been taken to measure. Organizational commitment to change measuring by using the items from the scale developed by Herscovitch and Meyer (2002). Environmental dynamism references the rate of change and the degree of instability of the environment (Dess \& Beard 1984). It creates current products and services old-fashioned and necessitate new to be developed (Jansen et al. 2005; Sorensen \& Stuart 2000). Environmental dynamism was operationalized in many previous outcomes (Miller \& Friesen, 1983; Dess \& Beard, 1984), but consensus has not emerged around one standard measure. In this study, we adopt and use a set of items that have been used by (Omri ,2005).

As Degirmenci and Breitner (2017) conducted, PLS-based structural equation modelling (SEM) is used to analyze the collected data. SmartPLS-SEM tool was used to analyze the data. It focuses on explaining the variance within the dependent variables when examining the model. an essential difference between these two approaches is how each method treats the latent variables included within the model. On the other hand, PLS-SEM uses proxies of interest weighted as composites of indicator variables for a specific construct (Janadari, Sri Ramalu, \& Wei, 2016).

\section{Findings}

According to (Malhotra, 2004) content validity is a subjective test, but a systematic estimate of fit the content of the scale represents the measurement task at hand. This can be explained by examining a panel of experts to check whether the items suitably describe the constructs being measured in the context of the research. Firstly, the questions were distributed to peers. This group consists of employees representing every sector in the aviation industry included in this study. They have examined the wordings of the questioner, flow of questioner and other suggestions and improvements and concluded that the set of questions are easy to understand and valid according to the sample.

A pilot study is a carryout to check the reliability and validity of the research instrument. Cronbach's alpha is the best way to measure items' internal consistency (Nunnally \& Bernstein, 2017). According to them, Cronbach's alpha value should be in 0.7 above is considered a sufficient amount. The confirmatory factor analysis (CFA) and expletory factor analysis (EFA) were carried out to examine the questionnaire's convergent validity and discriminant validity. A total of 35 questionnaires from front line staff of the aviation industry in Sri Lanka was collected to analyse the pilot test. The results of the pilot study reliability test and item-total correlation analysis are explained in results of the variables of selfawareness is above $0.7(\alpha=0.919)$, selfmanagement is above $0.7(\alpha=0.921)$, commitment to change is above $0.7(\alpha=$ 0.943), environmental dynamism is above 
$0.7(\alpha=0.874)$. As per the results, all variables have been maintained the internal reliability, where Cronbach's alpha is above 0.7 . The validity of the questioner measured by the Kaiser-Meyer-Olkin (KMO), and the amounts are above 0.7 (Cerny \& Kaiser, 1977). All these variables satisfy the standard requirement of a minimum value of 0.7 .

According to the confirmatory factor analysis conducted for the pilot study, the Average Variance Extracted (AVE) and the composite reliability measures used to appraise the construct validity. According to the results, all the constructs AVE and CR values are above the acceptable, and it is more than 0.5 and 0.7 , validity measures are well within the range.

After analysing the pilot study, the researchers distributed the questionnaire to the 330 respondents and collected the survey questionnaires. Then to the cleaning process for the purpose to identify outliers and provide treatments for missing values. Afterwards, they were subjected to the cleaning process. The data for this research was collected by using self-administered questionnaires distributed online.

According to Tabachnick and Fidell (1996), certain assumptions need to be compulsorily satisfied to perform multivariate analysis. According to Hair et al. (2010), deviation of normality, homoscedasticity, linearity and multicollinearity is misinterpreted as the correlation between variables. Therefore, before the factor analysis and SEM analysis being performed, the normality, homoscedasticity, linearity and multicollinearity were tested.

Normality represents the shape of the sample data scattering to the population. Kolmogorov-Smirnov test and Shapiro-Wilk test, the p-value should be significant, and it should be greater than 0.05 to confirm normality of the data set (Chinna \& Yuen, 2016). They correspond to the analysis of skewness values that do not fit in the -1.96 and +1.96 range. In the KolmogorovSmirnov test, the $\mathrm{P}$ values are less than 0.05 and reflect that each variable's data is not normally distributed. According to the results of the linearity, the $F$ values of linearity could not fulfil the requirement. The tolerance value is less than 0.10 and VIF more than 10 . It assumes that all explanatory variables are free from multicollinearity issues. This revealed that all the values are well within the acceptable threshold limits. For the current study, the standard probability plot and scatterplot were used to test the homoscedasticity of data further, showing the homoscedasticity of the relationship between variables. With the above analyses, the researcher chose the current study by using Smart-PLS to identify the impact of selfawareness and self-management factors affecting organizational commitment to change during and environmental dynamism.

\section{Confirmatory tetrad analysis (CTA)}

PLS-SEM, both measurement and outer model and structural or inner model, were assessed by the researcher. First of all, as a fundamental requirement of measurement model according to Hair at all. (2017), it should be ensured whether constructs are reflective or formative measured. Initially, it was supported theoretically and empirically (Janadari, Sri Ramalu, \& Wei, 2016) and then it was statistically confirmed by PLSconfirmatory tetrad analysis (CTA). The CTA results were explained in the analysis chapter based on the specifications recommended by Hair et al. (2018).

\section{Table 01: Final assumptions of CTA analysis}

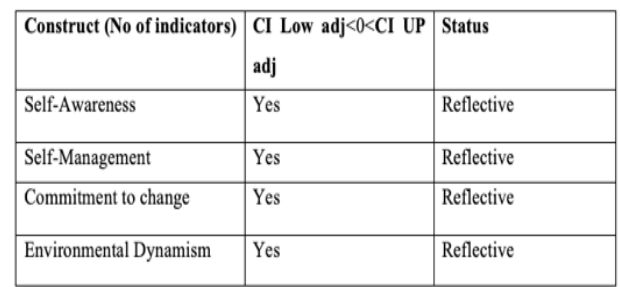

Source: Survey data, 2020 
As per above Table 01, the bias-corrected and Bonferroni-adjusted confidence intervals explain whether the non-redundant tetrads are significantly different from zero. The uppermost and lowers bounds of the $90 \%$ bias-corrected and Bonferroni-adjusted confidence intervals (CI Low adj. and CI UP adj) were listed in the results report.

\section{Model fit summary}

The PLS-SEM-based model fit measures such as SRMR, RMStheta, and the exact fit test has should be considered. When the outer model and inner model being tested, the model fit summery is presented. According to Hair et al, (2019), the below table has been prepared as shown in Table 02.

Table 02: Model fit summary

\begin{tabular}{|l|l|l|}
\hline & Saturated Model & Estimated Model \\
\hline SRMR & 0.048 & 0.048 \\
\hline d_ULS & 1.212 & 1.239 \\
\hline d_G & 0.554 & 0.615 \\
\hline Chi-Square & 1062.440 & 1265.139 \\
\hline NFI & 0.875 & 0.851 \\
\hline rms Theta & 0.119 & \\
\hline
\end{tabular}

Source: Survey data, 2020

According to the above testing, SRMR, RMStheta, or the exact fit test value indicates good fit (Hair et al., 2017). It successfully evaluated the measurement model (outer model), and structural model (inner model) confirmed the values are well within the acceptable limits, the hypotheses testing was carried out.

\section{Table 03: Assessment of internal consistency reliability}

\begin{tabular}{|l|l|l|l|l|l|l|}
\hline Construct & AVE & $\begin{array}{l}\text { Composite } \\
\text { Reliability }\end{array}$ & Rho_A & $\begin{array}{l}\text { Cronbach } \\
\text { Alpha }\end{array}$ & HTMT & $\begin{array}{l}\text { Fornell- } \\
\text { Larcker }\end{array}$ \\
\hline ED & 0.757 & 0.925 & 0.974 & 0.894 & & 0.870 \\
\hline EISA & 0.682 & 0.937 & 0.937 & 0.923 & 0.422 & 0.673 \\
\hline EISM & 0.561 & 0.863 & 0.898 & 0.820 & 0.312 & 0.583 \\
\hline OCC & 0.922 & 0.986 & 0.984 & 0.983 & 0.247 & 0.960 \\
\hline $\begin{array}{l}\text { Reference } \\
\text { Value }\end{array}$ & $>0.5$ & $>0.70$ & $>0.70$ & $>0.60$ & $<0.90$ & $<0.90$ \\
\hline
\end{tabular}

Source: Survey data, 2020
Consequently, under the reflectively measured variables, three significant criteria were measured: internal consistency, convergent validity, and discriminant validity. The assessment model can be considered as a reflectively measured model. All the constructs are above 0.50 due to that AVE values are acceptable. The discriminant validity, calculated by using exploiting two essential methods named Fornell-Larcker criterion and Heterotrait- Monotrait ratio. The HTMT values mention that all values are less than 0.90 therefore, no discriminant issues appear. The R2 value of the "organizational commitment to change" variable value than the required value.

\section{Correlation Analysis between Variables}

Pearson Correlation Coefficient matrix was used to establish a relationship between selfawareness and self-management on organizational commitment to change. According to Obilor, Esezi; Amadi; Eric (2018), the larger the p-value, the stronger the relationship and a smaller $\mathrm{p}$-value denote a more significant relationship. A correlation coefficient of -1 and +1 indicates perfect negative and perfect positive correlation, respectively. If Pearson's $r$ is zero, there is absolutely no association or zero correlation between the variables.

\section{Table 04: Correlation Analysis}

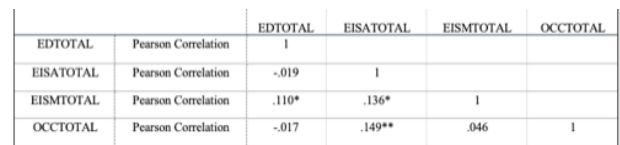

**. Correlation is significant at the 0.01 level (2-tailed). *. Correlation is significant at the 0.05 level (2-tailed).

\section{Hypothesis testing}

For the hypothesis testing two main hypotheses were developed according to the literature. Considering the relationship, all two variables such as self-awareness, selfmanagement were considered together as a composite variable. As a moderating factor 
environmental dynamism as a moderating variable to the relationship between emotional intelligence and organizational commitment to change. Accordingly, as per the PLS-SEM output, four hypotheses were introduced to the main conceptual framework but in deeper consideration.

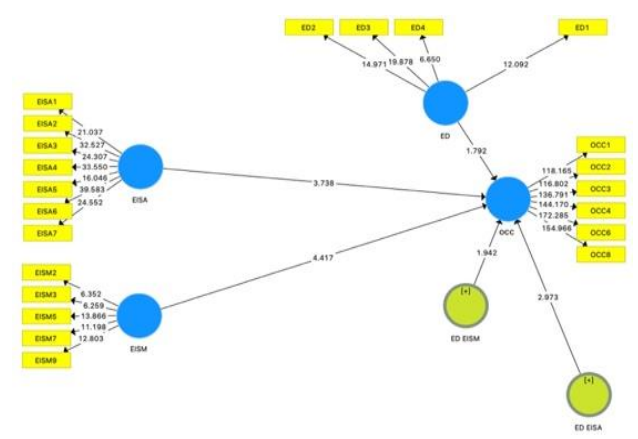

Figure 02: PLS-SEM Bootstrapping diagram

Source: Survey data, 2020

Table 05: Summary of H1, H2, $\mathrm{H3}$ and H4

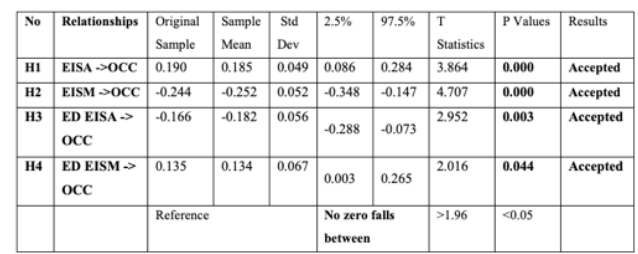

Source: Survey data, 2020

According to the results represented in the above table, the hypotheses except for relationship management other selfawareness are self-management accepted. A significant relationship between selfawareness and organizational commitment to change with a p-value of 0.000 that is less than $<0.05$ reject the null hypothesis $\mathrm{p}<0.05$ means that the null hypothesis of no impact is rejected. According to the result, there is a significant relationship between selfregulation and organizational commitment to change p-value of 0.000 , which is less than $<0.05$. Therefore, reject the null hypothesis. Accordingly, there is a significant impact regarding the effect of self-management on the organizational commitment to change.

Summary of Hypotheses testing Table V shows the relationship between emotional intelligence and organizational commitment to change the moderating effect of environmental dynamism. Self-awareness and organizational commitment to change is accepted at the 0.003 level, and that is significant has a moderating effect with environmental dynamism. Self-management and organizational commitment to change are accepted at 0.044 level and significantly positively affect environmental dynamism.

\section{Simple slopes analysis of moderating effects of EISA on OCC}

As mentioned in the above paragraph, the moderating effect of the ED on the relationship can be further discussed using simple slope analysis.

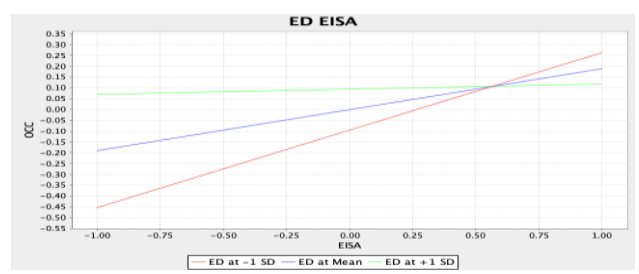

Figure 03: Moderating effects of EISA on ED

Source: Survey data, 2020

As shown in Figure III, the three lines represent the relationship between EISA ( $\mathrm{x}$ axis) and OCC (y-axis). The middle line illustrates the relationship for an average level of the moderator variable ED. The other two lines represent the relationship between EISA and OCC for higher (The mean value of ED when one unit is added to one unit) and lower (The mean value of ED when one is reduced) levels of the moderator variable ED. The figure shows that the higher ED levels lead to a week relationship between EISA and OCC. In contrast, lower levels of ED entail a higher relationship between EISA and OCC. 


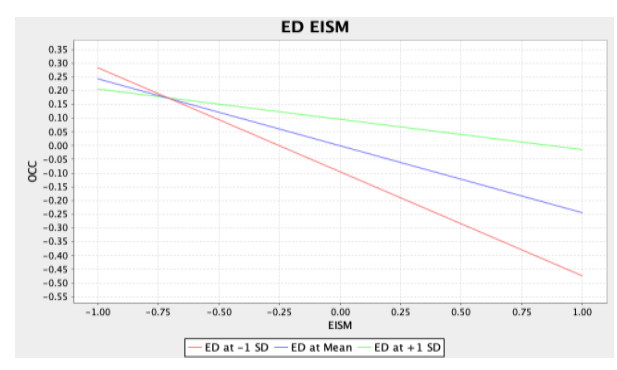

Figure 04: Simple slopes analysis of moderating effects of EISA on OCC Source: Survey data, 2020

Similarly, as discussed above paragraph, it can be shown that higher ED levels lead to a higher relationship between EISM and OCC. In comparison, lower levels of ED entail a week relationship between EISM and OCC.

\section{Importance-performance map analysis (IPMA)}

The importance-performance map analysis (IPMA) delivers the results of PLS-SEM by also considering the performance of each construct into account (Hair et al. 2012; Hair et al. 2018).

According to Unstandardized effects (Constructs) IPMA, reasonably argued that the EISA must be improved to enhance the organizational commitment to change in the aviation industry in Sri Lanka.

Table 06: Summary of the IMPA data

\begin{tabular}{|l|l|l|}
\hline & Importance (Total effects) & Performance \\
\hline EISA & 0.411 & 71.933 \\
\hline EISM & 0.673 & 64.032 \\
\hline ED & 0.188 & 72.017 \\
\hline
\end{tabular}

Source: Survey data, 2020

Each construct's total effects and performance for self-awareness and selfmanagement improvement are collected from the average latent variable scores of the constructs. The Performance of EISA increased from 71.9 to 72.9 , which would increase the performance of OCC by 0.411 points. Performance of EISM increased from 64.0 to 65.0 , which would increase the performance of OCC by 0.673 points. Hence, when managers aim at increasing the performance of the target construct OCC, their priority should be to improve the performance of aspects captured by EISA followed by EISM.

\section{Discussions}

The basic aim of this research was to identify the impact of emotional intelligence and organizational commitment to change on environmental dynamism in the aviation industry in Sri Lanka. To examine whether employees high in self-awareness and selfregulation would be more likely to meet the organizational commitment requiring frontline staff with a dynamist environment. Based on the current study, independent variables named self-awareness, selfmanagement is positively correlated with organizational commitment to change. The relationship between self-management and organizational commitment to change is $\mathrm{p}<0.00$ significant, and the relationship between self-awareness and organizational commitment to change significantly at $\mathrm{p}$ $>0.05$ level. Previous literature found that the relationship between self-awareness and organizational commitment to change has a positive relationship. A study conducted using teachers as emotional labour in Malaysia shows a strong and significant relationship between self-awareness and organizational commitment (Mohamad \& Jais, 2016). The results of these constructs are consistent with the previous findings. A study based on self-awareness and commitment for three industrial sub-sectors in rivers has explored a highly positive sign and meaningful relationship between selfawareness and commitment (Don, 2017). These results were consistent with previous studies that self-awareness is associated with organizational commitment (Mohamadkhani \& Lalardi, 2012). This study discovered that an escalation in self-management was greatly associated with a higher degree of commitment (Goffin \& Gellatly, 2001). 
This study suggests that environmental dynamism has a moderating effect on the relationship mentioned above. According to analysis, it is discovered that the moderation effect of environmental dynamism on the relationship between Self-awareness, selfmanagement and organizational commitment to change is significant and positive. A study based on hospitality and service management provides information on employee performance, affected by Self-awareness, self-management and both directly and indirectly to environmental uncertainty (Mahlagha, Levent, \& Glauco, 2018). Previous studies show that in this dynamic, demanding and dynamism environment, augmenting high emotional intelligence is necessary. It is a significant predictor of creativity since it is essential to manage the external and internal challenges in the organization.

According to the results, employees with high emotional intelligence are more committed to their organization. Therefore, emotional intelligence is one of the essential features that should be measured and practice within organizations, particularly when organizations need to assess the strengths and limitations of employees in response to change.

\section{Recommendations}

The service sector mainly focuses and formulated with an industry specialist to provide the best service to customers. A customer is a person who needs the best service for the money that they spent. The aviation industry plays a central role in the service sector because the aviation industry focuses on service and the safety of its customers. The aviation sector aims at their passenger's satisfaction, safety, service and customer retention for the benefit of an airline. Simultaneously, employees should ensure quality service and customer satisfaction in keeping any reaction of their passengers whether they are behaviour will be disruptive or not since customers perception of an airline service quality shapes competitive strategy in commercial aviation (Zeithaml, Parasuraman, \& Berry, 1990).

The self-awareness and self-management factors are significantly and positively predicting organizational commitment to change. The results indicate that high selfawareness, self-management is strongly linked to a commitment to change, which discloses the importance of high employees' emotional intelligence in their outcome. Consistent with theory, individuals' differences in self-awareness, selfmanagement influence each stage of the emotional experience, such as environmental uncertainty, which eventually influences organizational commitment to change. High in self-awareness, self-management capacity can contribute to employees' commitment by providing employees' cognitive actions such as reasoning, understanding, decisionmaking, and problem-solving (Jafri, Dem, \& Choden, 2016). This study contributes positive outcomes from employees with high self-awareness and self-management during external and internal uncertainty.

Changing practices such as learning to approach people may positively instead of avoiding them, listening better, or giving feedback will be more complex than implementing new practices to old habits. Self-awareness and self-management learning include the ways of thinking and acting unique to that person's identity. The prospect of introducing emotional competence is a bitter pill for many organizations to swallow. It will be much more likely to generate resistance to change.

An environmental dynamism organization should implement training programs to develop positive emotions during the change to obtain an employee commitment during change (Jain et al., 2018,2018,2020). The construct of self-awareness, selfmanagement could be explored with other constructs such as psychological well-being in order for employees to cope better with the demands of their jobs. Psychological support the well-being of the front-line staff should 
also be attended to. There should be a flow that describes the optimal process for helping individuals to increase their emotional competence in personal and interpersonal contexts.

Figure 05: Process of Developing Selfawareness, self-management in

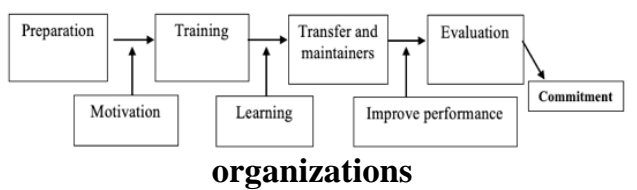

Figure 05 indicates that there are four steps to the training process. The preparation stage is crucial for effective emotional learning, involves preparation for change new behaviour. The preparation stage is on the organizational level and individual level. Moreover, applying this guideline to emotional intelligence training efforts is to identify all of the particular competencies important for success. For example, aviation industry-related organizations such as airlines and airports are similar in price structure. However, competitive advantage depends mainly on how well passengers are treated by airline or airport personnel. As a result, how flight attendants dealt with passengers became a focal point for training and interpersonal and self-management: resilience, efficiency, and adaptability. Selfawareness and empathy are caring for and managing customers well and teamwork. In addition, a training program is required. Determine employees' level of readiness. According to research on a range of behaviour modification programs, people go through various phases of preparedness for change before they are ready to make a meaningful commitment. They deny the new change in the first stage. People begin to see that they need to better in the following stage, but they are unsure that anything can be done about their difficulties, so they postpone making a decision.

The second step, the training process, involves the changing process, which includes the processes that help people change. Such as how they view others and deal with their emotional demands. Motivation is still a significant factor in social and emotional learning during the training period. Since the amount of time, effort, and possible challenges to one's selfesteem that occur throughout social and emotional learning, trainers should continue to evaluate the individual's motivation and intervene to help them succeed. The most effective trainers can help the learners set clear and challenging goals without infringing on the learner's sense of ownership. This way, the goal of increasing self-confidence the goals. The larger goal of the setting of new, more challenging goals. Became attainable, and steady progress and success rather than frustration and failure characterized the process. One of the most typical mistakes made in social and emotional learning programs is to have a seminar or workshop on a single day. Unfortunately, even a multi-day intensive course is rarely enough to help people unlearn old, ingrained behaviours and build new ones that will remain. The most effective training programs incorporate several practice and feedback sessions.

The next step, transfer and maintenance, shows the outcome of following the formal training experience. Many signals and reinforcers are likely to promote the old brain pathways that training was supposed to weaken when learners return to their native settings. Furthermore, some of the new social and emotional capabilities still being developed may face considerable challenges.

The final step indicates the evaluation process. It provides the current state of knowledge about social and emotional learning, the complexity of programs designed to promote such learning and the extraordinary unevenness in the effectiveness of existing programs. Evaluation always should be part of the process. Employee performance appraisal should also consider the employees' EI abilities so that those who successfully apply these abilities on the job are appropriately rewarded. 
Apart from the above process, management should remain flexible and prevent reconciling ideas and emotions from becoming too rigid when there is a change in the industry, competition or passenger's expectation. Management should bring new hope and life to the organization by judicious employee turnover and welcoming newcomers.

Improve good communication policies during a change is important (CAA,2006). Management should communicate and educate employees regarding changes happening at the organization. Organizations should endeavour to put proper communication policies and structures that would aid the proper dissemination of change programmes when they intend to undertake one. This is important because communication is crucial to the success of every new strategy that a firm decides to venture into, including change.

This study explains the contribution of each variable in a varying environment, and consequently, there are specific theoretical implications. This study contributes essential input to the existing literature in hospitality and service management (Kim \& Agrusa, 2011). Vert few empirical readings explored self-awareness, self-management, commitment to change and environmental dynamism in the aviation industry. To address the gap, this study examined selfawareness, self-management as an impact of organizational commitment to change, the moderating role of environmental dynamism among front line staff of the aviation industry in Sri Lanka.

The findings of this study provide information on the importance of EI on frontline employees' commitment. Very few studies explored the combination through which self-awareness, self-management leads to commitment in an uncertain environment (Ameriks, Wranik, \& Salovey, 2009). The emotions of frontline employees play a significant role in their customer's satisfaction and service quality from the customer's perspective. This is due to frontline service employees interact directly with them (Sergeant \& Frenkel, 2000)

Empirical research evidence that employees with high self-awareness are more committed to their organization and environmental conditions (Goleman,1995). Accordingly, employees with high self-management are successful in adapting themes to organizational and any environmental conditions, and they're committed to their organization (Elizabeth, Charles, \& Stephen, 2006)

Scientific evidence proves that emotional intelligence has a significant impact on individuals' commitment and that balance of emotion is the most vital strategy for an uncertain environment (Salovey \& Mayer, 1990). According to social learning theory, persons' knowledge and capability should be directly linked to observant others within the context of social relations and proficiencies (Barry \& Zimmerman, 1995). Self-awareness and self-management are that efficient and effect when in an uncertain environment (Dominguez, 2013).

\section{Limitation and direction for future research}

Apart from the findings of this study, one of the main limitations of this study is that Sri Lanka has only one national carrier, even though this includes several airports. Respondents are limited to one airline. If this kind of study included a larger population, that would be more significant. Furthermore, the questionnaire does not include qualitative data. Interviews with leaders and subordinates of the organization would include this sample. It may have improved the quality of this research by adding a better understanding of the individuals' natural emotions. Therefore, future research needs to use both quantitative and qualitative data in order to find out a complete overview. Furthermore, additional research needs to explore other potential mediating and moderating variables. Future research can 
also be conduct to replicate the same analysis by using new statistical techniques. In addition to self-awareness and selfmanagement factors, further studies can apply other related factors to the organizational commitment to change. Next, the data was only cross-sectional. If the data were longitudinal, collecting data at different times and creating different data points would give a more effective outcome.

\section{Conclusion}

The purpose of this current study was to find out whether there is a relationship between self-awareness, self-management and organizational commitment to change and the effect of environmental dynamism in this relationship among front line staff in the aviation industry in Sri Lanka. Furthermore, in line with social learning theory findings, elaborate the previous studies. These results provide that self-awareness and selfmanagement employees can predict environmental uncertainty, adapt to these environmental changes, solve problems and situational awareness during environmental dynamism. Therefore, these employees are committed to change (Armenakis, Harris, \& Feild, 1999). The current study, empirical evidence shows that the overall concept of self-awareness, self-regulation has a statistically positive and significant influence on organizational commitment to change.

\section{References}

Ajzen, I. (2001). Nature and operations of attitudes. Annual Review of Psychology, 27-58. https://doi.org/10.1146/annurev.psych.52.1.27

Almer, B., Walls, M., Burgess, Z., \& Stough, C. (2001). Emotional intelligence and effective leadership. Leadership \& Organization Development Journal 22(1), 5-10. https://doi.org/10.1108/01437730110380174

Ameriks, J., Wranik, T., \& Salovey, P. (2009). Emotional Intelligence and Investor Behavior. Charlottesville: The Research Foundation of CFA Institute.

Bandura, A. (1997). Self-efficacy: The exercise of control. New York. https://doi.org/10.1891/0889-8391.13.2.158

Baridam, 1. (2017). Emotional intelligence and organizational commitment in three industrial sub-sectors in rivers state. International Journal of Advanced Academic Research | Social \& Management Science, Page 1.

Barry, J., \& Zimmerman, A. S. (1995). Self-monitoring during collegiate studying: An invaluable tool for academic self-regulation. Autumn (Fall), 13-27. https://doi.org/10.1002/tl.37219956305

Belsley, D., Kuh, E., \& Wiklund, I. (1980). Regression Diagnostics: Identifying Influential Data and Source of Collinearity. New York;Wiley.

Ben-Gal, I. (2005). Outlier Detection. Data Mining and Knowledge Discovery Handbook.

Bobby, C. (2021). 27 Astonishing E-learning Statistics for 2020. Techhurry.

Bryman, A., \& Bell, E. (2007). Business Research Methods. Oxford University Press. 
Burns, D., \& Neisner, L. (2006). Customer satisfaction in a retail setting: The contribution of emotion. International Journal of Retail and Distribution Management. 49-66. https://doi.org/10.1108/09590550610642819

Carmines, E. G., \& McIver, J. ,. (1981). Analyzing Models with Unobserved Variables. Analysis of Covariance Structures, 65-115

Cathy, L., \& Farah, L. (2020, April 29). world economic forum. Retrieved from world economic forum web site: https://www.weforum.org/agenda/2020/04/coronavirus-educationglobal-covid19-online-digital-learning/

Cerny, B., \& Kaiser, H. (1977). A study of a measure of sampling adequacy for factor-analytic correlation matrices. Multivariate Behavioral Research, 43-47. https://doi.org/10.1207/s15327906mbr1201_3

Cherniss, C. (2010). Emotional intelligence: toward clarification of a concept. Ind. Psychol. 3 (2), 110-126. https://doi.org/10.1111/j.1754-9434.2010.01231.x[Opens in a new window]

Chinna, K., \& Yuen, C. (2016). Statistical Analysis using SPSS. Kuala Lumpur: Pearson Malaysia Sdn Bhd. https://doi.org/10.1053/j.jrn.2019.09.010

D, G. (1998). Working with emotional intelligence. New York: Bantam Books.

Diamond, G. A. (1992). Field theory and rational choice: a Lewinian approach to modeling motivation. Journal of Social Issues, 48, 79-94. https://doi.org/10.1111/j.15404560.1992.tb00885.x

Dijkstra, T. (2010). Latent variables and indices: Herman Wold's basic design and partial • least squares. Handbook of partial least squares: Concepts, methods and applications in marketin. https://doi.org/10.1007/978-3-540-32827-8_2

Elizabeth, J., Charles, E., \& R. Stephen, P. (2006). Emotional Intelligence and Dispositional Affectivity as Predictors of Performance in Salespeople. The Journal of Marketing Theory and Practice, 113-124. https://doi.org/10.2753/MTP1069-6679140202

Ensley, m. d., Pearce, c. 1., \& Hmieleski, k. (2006). The moderating effect of environmental dynamism on the relationship between entrepreneur leadership behavior and new venture performance. Journal of Business Venturing, 243-263. https://doi.org/10.1016/j.jbusvent.2005.04.006

Foote, D., Seipel, S., Duffy, M., \& Johnson, M. (2005). Employee commitment and organizational policies. Management Decisions, 43, 203-219. https://doi.org/10.1108/00251740510581920

Gagné, M., Chemolli, E., Forest, J., \& Koestner, R. ((2008). A temporal analysis of the relation between organisational commitment and work motivation. Psychologica Belgica. https://doi.org/10.1007/978-3-540-32827-8_2

Garson, G. (2011). Structural Equation Modeling. Statnotes. https://doi.org/10.5897/AJAR10.621 
George, D., \& Mallery, P. (2003). SPSS for Windows step by step: A simple guide and reference11.0 update (4th ed.). Boston: Allyn \& Bacon.

Goffin, R., \& Gellatly, I. (2001). A multi-rater assessment of organizational commitment:Are self-report measures biased? Journal ofOrganizational Behavior, 437-451. https://doi.org/10.1002/job.94

Goleman, D. (2001). The Emotional Intelligent Workplace. p.28. https://doi.org/10.1108/LM10-2012-0072

Gudergan, S., Ringle, C., Wende, S., \& Will, A. (2008). Confirmatory Tetrad Analysis in PLS Path Modeling. Journal of Business Research, , 61 (12),., 238-1249. https://doi.org/10.1016/j.jbusres.2008.01.012

GuderGan, S., Ringle, C., Wende, S., \& Will, A. (2008). Confirmatory Tetrad Analysis in PLS Path Modeling. Journal of Business Research, 61 (12), 238-1249. https://doi.org/10.1016/j.jbusres.2008.01.012

Haenlein, M., \& Kaplan, A. (2004). A beginner's guide to partial least squares analysis. Understanding Statistics, 283-297. https://doi.org/10.1207/s15328031us0304_4

Hair. (2018). Advanced Issues in Partial Least Squares Structural Equation Modeling (PLSSEM). CA Saga: Thousand Oaks.

Hair, J. F., Ringle, C., \& Sarstedt, M. (2013). Partial least squares structural equation modeling: rigorous applications, better results and higher acceptance",. Long Range Planning. Vol. 46 Nos 1/2, , pp. 1-12. https://doi.org/10.1108/EBR-10-2013-0128

Hair, J., \& Black, W. (2010). EMultivariate data analysis. Upper Saddle River, NJ: Pearson Education Inc. http://doi.org/10.5539/ass.v10n10p76

Hair, J., Risher, J., Sarstedt, M., \& Ringle, C. (2019). When to use and how to report the results of PLS-SEM. European Business Review, Vol. 31 No.1, 2 - 24. https://doi.org/10.1108/EBR-11-2018-0203

Harrington, R. (2001). Environmental uncertainty within the hospitality industry: ex- ploring the measure of dynamism and complexity between restaurant segments. Hosp. Tourism Adm, 386-398.

Hayashi, R., Marito, M., \& Hewagamage, K. (2020). Online Learning in Sri Lanka's Higher Education Institutions during the COVID-19 Pandemic. DOI: http://dx.doi.org/10.22617/BRF200260-2

Higgs, M. (2004). A study of the relationship between emotional intelligence and performance in UK call centres. Journal of Managerial Psychology, 442-454. https://doi.org/10.1108/02683940410537972

Hochschild, A. (1983). The Managed Heart: Commercialization of Human Feeling. Berkeley: University of California Press. 
Warnakula, U.S., Dhammika, K.A.S., Karunarathne, R.A.I.C., KJM, 2021, 10 (02)

Hossein, S. F., \& Hakimeh, T. (2015). Relationship between managers' emotional intelligence and organizational. Research Journal of Recent Sciences, 10-15. https://doi.org/10.1007/s13520-020-00110-x

Hu, L., \& Bentler, P. (1999). Cutoff Criteria for Fit Indexes in Covariance Structure Analysis: Conventional Criteria Versus New Alternatives, Structural Equation Modeling. 1-55. https://doi.org/10.1080/10705519909540118

Hulland, J. (1999). Use of partial least squares (PLS) in strategic management research: a review of four recent studies. Strategic Management Journal, 195-204. https://doi.org/10.1002/(SICI)1097-0266(199902)20:2<195::AID-SMJ13>3.0.CO;2-7

Huy, Q. (1999.). Emotional capability, emotional intelligence, and radical change. Academy of Management Review 24, 325-345. https://doi.org/10.5465/amr.1999.1893939

Jafri, M., Dem, C., \& Choden, S. (2016). Emotional intelligence and employee creativity: moderating role of proactive personality and organizational climate. Bus. Perspect. Res. 4, 54-66.

Jain, Duggal, Stoian, Kolnhofer, D., Nagy, \& Javaria. (2018,2018,2020). Transformational leadership, organizational commitment, emotional intelligence and job autonomy: Empirical analysis on the moderating and mediating variables. Management-Research-Review-20408269. https://doi.org/10.1108/MRR-01-2018-0029

Janadari, M. P., Sri Ramalu, S., \& Wei, c. (2016). Evaluation of measurment and structural model of the reflective model constructs in PLS - SEM. South Eastern University of Sri Lanka.

Joreskog, K. G., \& Wold, H. (1982). The ML and PLS techniques for modeling with latent variables: Historical and comparative aspects. Amsterdam: North-Holla: Systems under indirect observations: Part I.

Joshua, S. (n.d.). Introduction to Online Teaching and Learning. Retrieved from http://www.wlac.edu/online/documents/otl.pdf:http://www.sloan-c.org/resources/index.asp)

Kernbach, S., \& Schutte, N. (2005). The impact of service provider emotional intelligence on customer satisfaction. The Journal of Services Marketing, 438-444. https://doi.org/10.1108/08876040510625945

Kim, H., \& Agrusa, J. (2011). Hospitality service employees' coping styles: the role of emotional intelligence, two basic personality traits, and socio-demographic factors. 588-59. https://doi.org/10.1016/j.ijhm.2010.11.003

Kline, R. B. (1998). Principles and Practice of Structural Equation Modeling, Guilford Press. Retrieved from www.riceexhibition.com: Rice International Conference \& Exhibition portal

Kusluvan, S. (2003). Managing Employee Attitudes and Behaviors in the Tourism and Hospitality Industry. New York: Nova Publishers. 
L, H., \& Meyer J, P. (2002). Commitment to organizational change: Extension of a threecomponent model. Journal of Applied Psychology, 87:474-487. https://doi.org/10.1037/00219010.87.3.474

Li, D., \& Liu, J. (2014). Dynamic capabilities, environmental dyna- mism, and competitive advantage: evidence from China. Journal of Business Research, 67, 2793-2799. https://doi.org/10.1016/j.jbusres.2012.08.007

Lohmöller, J. (1989). Latent Variable Path Modeling with Partial Least Squares. Heidelberg.: Physica.

Mack, B. (2014). Airlines struggle to serve sustainability. https://p.dw.com/p/1CeZm.

Madsen S, R., D, M., \& John C, R. (2005). Readiness for organizational change: Do organizational commitment and social relationships in the workplace make a difference? Human Resource Development Quarterly. 16:213-233. https://doi.org/10.1002/hrdq.1134

Mahalanobis, P. (1936). On the generalized distance in statistics. Proc. Natl Inst. Sci. India, Vol. 2,p, 49-55.

Mahlagha, D., Levent, A., \& Glauco, D. (2018). Emotional intelligence and creative performance: Looking through the lens of environmental uncertainty and cultural intelligence . International Journal of Hospitality Management, 44-55. https://doi.org/10.1016/j.ijhm.2018.01.014

Malhotra, N. K. (2004). An Applied Orientation (4th ed.). Marketing Research.

McClendon, M. (2002). Multiple Regression and Causal Analysis. Long Grove, IL: Waveland Press.

McGuire, W. (1986). The vicissitudes of attitudes and similar representational constructs in twentieth century psychology. European Journal of Social Psychology, 16, 89- 130. https://doi.org/10.1002/ejsp.2420160202

Mohamad, M., \& Jais, J. (2016). Emotional intelligence and organizational commitment: A study among Malaysian teachers. Procedia Economics and Finance, 35, 674-682. https://doi.org/10.1016/S2212-5671(16)00083-6

Mohamadkhani, K., \& Lalardi, M. (2012). Emotional intelligence and organizational commitment between hotels staff in Tehran. American Journal of Business Management, 5459. https://doi.org/10.11634/21679606170693

Muntajeeb, A. (2011). A Critical Study Of Effectiveness Of Online Learning On Students Achievement. manager's Journal of Educational Technology, 28-34.

Murnieks, c. y., McMullen, j. s., \& Cardon, m. (2017). Does Congruence with an Entrepreneur Social Identity Encourage Positive Emotion Under Environmental Dynamism? Journal of Small Business Management. 
Narayanaswamy, V., \& Harinarayana, N. (2016). Conference: National Conference on "Scientific, Computational \& Information Research Trends in Engineering.

Nagahawatta, R., Warren, M. and Yeoh, W., 2020. A Study of Cyber Security Issues in Sri Lanka. International Journal of Cyber Warfare and Terrorism (IJCWT), 10(3), pp.59-72 http;//doi.org/0.4018/IJCWT.2020070105

Nunnally, J. C., \& Bernstein, I. H. (2017). The Assessment of Reliability. Psychometric Theory, 3. Modern Economy Vol.8 No.1, 248-292. https://doi.org/10.1108/JIBR-11-20160132

O’Boyle, E., Humphrey, R. H., Pollack, J. M., Hawver, T. H., \& Story, P. A. (2010). The relation between emotional intelligence and job performance: A meta-analysis. Journal of Organizational Behavior, 32(5), 788-818. https://doi.org/10.1002/job.714

O'Reilly, C., Caldwell, D., Chatman, J., Lapiz, M., \& Self, W. (2010). How leadership matters: the effects of leaders alignment on strategy implementation. The Leadership Quarterly, 104-113. https://doi.org/10.1016/j.leaqua.2009.10.008

Pallant, J. (2005). SPSS Survival Manual. Philadelphia: Open University Press. doi: $10.7748 / \mathrm{nr} .2016 . \mathrm{e} 1382$

Peter, M., Hewagamage, K., \& Henrik, H. (2011). Towards e-learning for all in Sri Lanka progress and problems in some selected Sri Lankan 21 st century initiatives. Researchgate.

Rathiranee, Y. (n.d.). Challenges in Online learning towards better learning environment: A Case study on Bachelor of Business Management (BBM) Online Degree Programme at University of Jaffna, Sri Lanka. http://ssrn.com/abstract=2429553, 2014.

Raykov, T. (2000). On the Large-Sample Bias, Variance, and Mean Squared Error of the Conventional Noncentrality Parameter Estimator of Covariance Structure Models, Structural Equation Modeling. 431-441. https://doi.org/10.1207/S15328007SEM0703_4

Ringle, C., Wende, S., \& Will, S. (2005). SmartPLS 2.0 (M3). Retrieved from http://www.smartpls.de

Santhidran, S., Chandran, V., \& Borromeo, J. (2013). Enabling organizational change leadership, commitment to change and the mediating role of change readiness. Journal of Business Economics and Management, 14(2), 348-363. https://doi.org/10.3846/16111699.2011.642083

Sapna Laxmi, T., Dilesh, P., Umesh, P., Pratik, M., \& Nuwadatta, S. (2020). Study on the effectiveness of online classes for undergraduate medical and dental students of Gandaki Medical College during COVID 19 pandemic period in Nepal. Orthodontic Journal of Nepal, Vol. 10 No. 2 COVID-19 Special Issue. https://doi.org/10.3126/ojn.v10i2.31146

Saunders, M., \& Lewis, P. (2012). Doing Research in Business and Management,An Essential Guide to Planning Your Project. Harlow: Pearson Education. 
Warnakula, U.S., Dhammika, K.A.S., Karunarathne, R.A.I.C., KJM, 2021, 10 (02)

Sekaran, U., \& Bougi, R. (2017). Research Methods for Business : A Skill-Buliding Approach 6th Ed. New Delhi: Wiley India Pvt Ltd.

Sergeant, A., \& Frenkel, S. (2000). When Do Customer Contact Employees Satisfy Customers? Journal of Service Research, 18-34.

Stamatis, D. (2001). Six Sigma and Beyond: The Implementation Process (Vol. VII). London: CRC Press.

Tang, C., \& Gao, Y. (2012). Intra-department communication and employees' reaction to organizational change: the moderating effect of emotional intelligence. Journal of Chinese Human Resource Management, 100-117. https://doi.org/10.1108/20408001211279210

Ullman, J. B. (2006). Structural equation modeling: Demystified and applied. Journal of Personality Assessment. http://dspace.bu.ac.th/jspui/handle/123456789/4597

United Nations Conference on Trade and Development. (2020, April 06). Retrieved from United Nations Conference on Trade and Development web site: https://unctad.org/news/coronavirus-reveals-need-bridge-digital-divide

Walters, B., \& Bhuian, S. (2004). "Complexity absorption and performance: a structural analysis of acute care hospitals". Journal of Management, Vol. 30, 97.

Wayne, W. (2019). Behavioral Change Models. Boston: Boston University School of Public Health,sphweb.bumc.bu.edu. https://doi.org/10.1186/s12889-019-6587-6

Zeithaml, V. A., Parasuraman, A., \& Berry, L. (1990). Delivering quality services: Balancing customer perceptions and expectations. New York: NY: Free Press. 